\title{
RELATIONSHIP OF PRECIPITATION AND HABITAT TO THE SPATIAL AND TEMPORAL ABUNDANCE OF AEDES ATLANTICUS AND AEDES INFIRMATUS IN ST. JOHNS COUNTY, FLORIDA
}

\author{
MADELINE STECK ${ }^{1,2}$, BERNARD OKECH', SONG LIANG', RUI-DE XUE², \\ AND WHITNEY A. QUALLS² \\ 'Department of Environmental and Global Health, College of Public Health \\ and Health Professions, University of Florida, Gainesville, FL 32611
}

${ }^{2}$ Anastasia Mosquito Control District, 120 EOC Drive, St. Augustine, FL 32092

\author{
Guest Editor: Mohamed F. Sallam
}

\begin{abstract}
The purpose of this study was to perform descriptive and inferential analyses to better understand the presence of the abundant mosquito species Aedes atlanticus and Aedes infirmatus in St. Johns County, northeastern Florida. Historical surveillance data (2010-2019) obtained from Anastasia Mosquito Control District of St. Johns County, St. Augustine, FL, was organized to graph temporal mosquito abundance trends and inverse distance weighted (IDW) interpolation was used to map spatial distribution patterns of mosquitoes. Precipitation and habitat composition were investigated as spatiotemporal predictors of mosquito abundance using Pearson's correlation statistics. There were considerable and inconsistent fluctuations in the population abundance of Ae. atlanticus and Ae. infirmatus across and within individual surveillance seasons during the last decade. Precipitation was significantly associated with total county-wide mosquito population counts by season (Ae. atlanticus, $\mathrm{R}=0.810, \mathrm{p}=0.005 ;$ Ae. infirmatus, $\mathrm{R}=$ $0.850, \mathrm{p}=0.002$ ), while the association with weekly mosquito population trends was inconsistently significant across species, lag time, and years. The proportion of surrounding land covered by upland forest, water, and agriculture was associated with species abundance at the spatial level of individual trap sites. Overall, the results identify that $A e$. atlanticus and Ae. infirmatus share a spatiotemporal relationship and are similarly impacted by rainfall and habitat type. Findings of the study might help to inform improved surveillance by integrating IDW estimation maps with current district resources and improved knowledge of species' ecology.
\end{abstract}

Key Words: Aedes atlanticus, Aedes infirmatus, GIS, spatial, temporal, precipitation, land cover

\section{INTRODUCTION}

Aedes atlanticus Dyar \& Knab and Aedes infirmatus Dyar \& Knab are floodwater mosquitoes that are aggressive biters and nuisance pests. There is field evidence that these mosquitoes are vectors for several arboviruses including keystone virus (KEYV) and eastern equine encephalitis virus (EEEV) (Bigler et al. 1976, Wellings et al. 1972, LeDuc et al. 1975, Roberts and Scanlon 1975). The high abundance of these two mosquito species in St. Johns County [AMCD 2017] combined with the detection of both KEYV and EEEV within county borders may pose a risk to public and veterinary health. However, the population distribution and ecological pat- terns of Ae. atlanticus and Ae. infirmatus in St. Johns County and the entirety of North Florida are not well described. Such knowledge could help to inform and improve surveillance and control programs in the county.

Geographic information systems (GIS) and remote sensing have emerged as powerful tools in mosquito control efforts by offering insights into geographic distribution and spatial clustering which help to understand historical patterns and overall dynamics of mosquito vector populations (Hungerford 1991) and arbovirus transmission (Sallam et al. 2016a, b). A spatiotemporal analysis can be used to determine static or dynamic hotspots of abundant mosquito populations and guide control efforts to predict and pre- 
emptively manage these areas. Additionally, it is equally important to observe and study the potential ecological drivers of mosquito distributions to better understand a species' presence and geographical movement. Such knowledge can be used to optimize surveillance and control programs, especially when considering ecological drivers of vector populations as indirect risk factors for arbovirus transmission.

The objective of this study was to explore the spatiotemporal distribution of Ae. atlanticus and Ae. infirmatus and examine potential ecological drivers of mosquito abundance and distribution in St. Johns County based on the historical surveillance records archived by Anastasia Mosquito Control District (AMCD) of St. Johns County, FL.

\section{MATERIALS AND METHODS}

Study Area. St. Johns County is located on the northeastern part of Florida and covers $1,650 \mathrm{~km}^{2}$ between the St. Johns River and the Atlantic Ocean coastline (Fig. 1). The region has a humid subtropical climate with an average high temperature of $90^{\circ} \mathrm{F}\left(32.2{ }^{\circ} \mathrm{C}\right)$ in the warmest month and an average low temperature of $46^{\circ} \mathrm{F}\left(7.8^{\circ} \mathrm{C}\right)$ in the coldest month (Weather Atlas). The environment is characterized by a range of salt and fresh water habitats and is classified as an Eastern

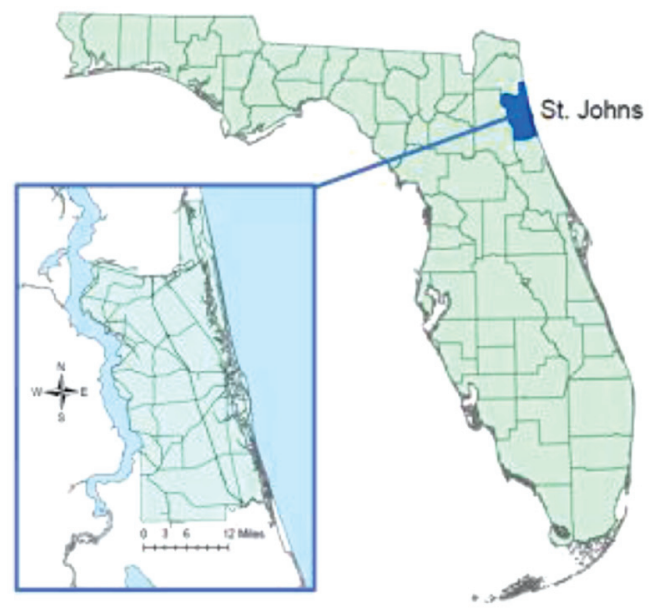

Figure 1. Map of Florida and county borders of St. Johns County, Florida
Florida Flatwoods Class IV ecoregion by the Environmental Protection Agency (United States Environmental Protection Agency). The population estimate for 2019 was 249,734 residents compared to an estimated 190,646 residents in 2010 (Florida Health Charts). Shapefiles of St. Johns County waterways, roads, and mosquito adulticide zones were retrieved from AMCD GIS archives.

Mosquito surveillance dataset. AMCD uses the U.S. Centers for Disease Control and Prevention (CDC) light traps (John Hock, Gainesville, FL) baited with octenol for its seasonal surveillance program which typically runs April-November every year. During 2010-2019 light traps were equipped with a plastic collection container with a pesticide stick, 12V battery, light bulb, and an octenol lure stick (synthetic semiochemical, Biosense). Traps were set out in designated field locations (one trap per site, number of sites dependent on season) once every week for approximately 24 hours. Afterwards, light traps and collections were transported to the AMCD laboratory for species identification and database recordkeeping using appropriate taxonomic keys (Darsie and Ward 2005).

Data preparation $\mathcal{E}$ exploratory data analysis. Historical CDC light trap surveillance data (2010-2019) were retrieved from AMCD database records. Spreadsheet data of weekly mosquito trap collections for a subset of years (2010, 2013, 2016, 2019) were reorganized, georeferenced, and compiled into total counts per week and per trap location for both Ae. atlanticus and Ae. infirmatus (Fig. 2a, b). The total sum of adult female mosquitoes collected at an individual or all CDC light trap sites over the course of a (standardized) surveillance season was used as a measure of total seasonal count. The standardization process entailed comparing the start and end dates of all surveillance seasons and tailoring a standard period that matched the shortest surveillance season (twenty-six weeks; early May-early November) to all years with approximately equivalent start/end dates. Mosquito counts that fell outside of these weeks for any year were excluded from all temporal and spatial analyses. Total seasonal 
(a)

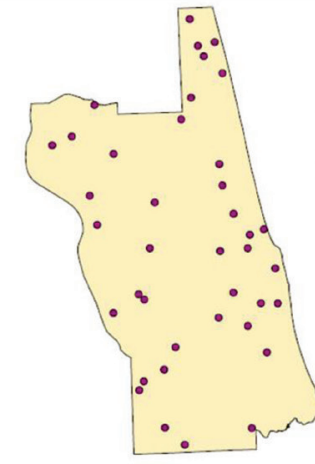

2010

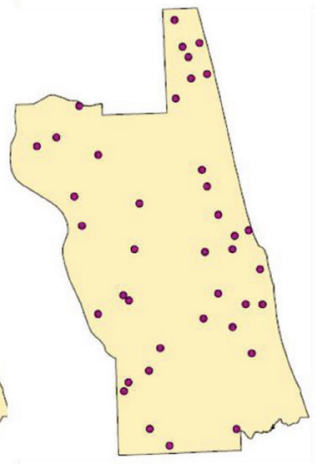

2013
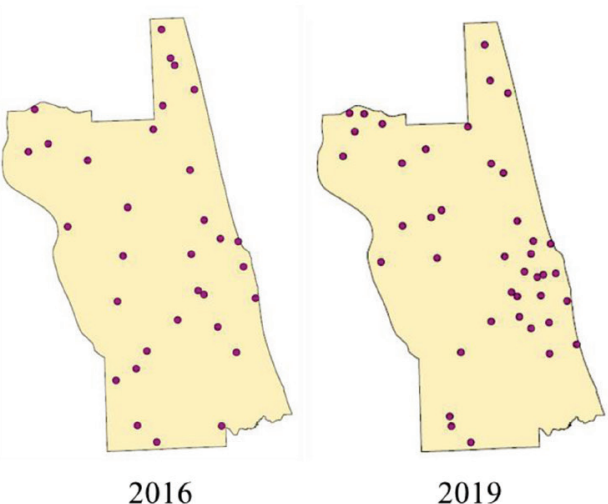

2019

(b)

\begin{tabular}{|lc|cc|cc|}
\hline \multicolumn{2}{|c|}{ Surveillance season } & \multicolumn{2}{|c|}{ Aedes atlanticus } & \multicolumn{2}{c|}{ Aedes infirmatus } \\
$\underline{\text { Year }}$ & $\underline{\text { No. traps }}$ & $\underline{\text { Min-Max }}$ & $\underline{\text { SD }}$ & $\underline{\text { Min-Max }}$ & $\underline{\text { SD }}$ \\
2010 & 39 & $0-599$ & 100.31 & $0-123$ & 28.38 \\
2013 & 39 & $0-5,910$ & $1,238.49$ & $0-227$ & 50.64 \\
2016 & 32 & $0-4,956$ & $1,094.25$ & $0-73$ & 16.2 \\
2019 & 41 & $0-768$ & 139.63 & $0-167$ & 32.39 \\
\hline
\end{tabular}

Figure 2. CDC light traps and spatial heterogeneity of mosquito abundance: (a) CDC light trap locations for the years 2010, 2013, 2016, and 2019. (b) Descriptive statistics of mosquito counts at 2010, 2013, 2016, and 2019 trap sites. The minimum, maximum, and standard deviation (Min, Max, SD) were calculated using the total count of mosquitoes collected at individual trap sites over each twenty-six-week season to emphasize spatial heterogeneity. Averaged seasonal abundances for each species during these years are listed in Table 1.

counts were then utilized as proxy measures for assuming total seasonal abundance at either an individual location or on a countywide scale. County-wide totals were averaged by the number of active trap sites in a given surveillance season to account for differences in number of traps deployed (Table 1). Four years of the ten-year timespan were initially singled out for spatiotemporal analyses due to a limited time capacity; however, early exploratory data analysis motivated the integration of total count data from the remaining six years of the decade in temporal analyses (not spatial) to better understand the fluctuations in county-wide trends across separate surveillance seasons.

One problem that arose was the presence of null values for weeks within the standardized season due to no trap collections that week for unknown or extreme weatherrelated reasons. Data imputation was used to overcome this issue by averaging the weekly county-wide abundance data between the prior week and following week surrounding a missing data point. Four years had no missing collection weeks while other years had one, two (most), or in one case three weeks missing. Other imputation techniques, such as averages for a particular collection week across the remaining ten years, did not produce valid estimates. Imputation was not used to replace missing weekly count values at individual trap sites and thus did not impact spatial analyses.

Due to observations from initial exploratory analyses, rainfall was chosen as a potential environmental predictor of temporal mosquito abundance. Daily and seasonal precipitation summaries (April 2010-Novermber 2020) were downloaded from the Hastings 4 NE, FL US GHCND: USC00083874 weather station in St. Johns County via the 
Table 1. The total and average abundance of Ae. atlanticus and Ae. infirmatus for every year 2010-2019 using the total combined count of all mosquitoes from all traps active during the twenty-six-week season. To describe the full timeline of 2010-2019, the minimum, maximum, mean, and standard deviation (Min, Max, Mean, SD) were calculated using the compiled averaged abundance of mosquitoes from all trap sites over each season (Average/ trap) across all years to emphasize temporal heterogeneity among separate surveillance seasons. Use of raw collection counts; imputed values were not included in the calculations of this table.

\begin{tabular}{|c|c|c|c|c|c|c|c|c|c|}
\hline \multicolumn{2}{|c|}{ Surveillance season } & \multicolumn{4}{|c|}{ Ae. atlanticus } & \multicolumn{4}{|c|}{ Ae. infirmatus } \\
\hline Year(s) & No. traps & \multicolumn{2}{|c|}{ Total } & \multicolumn{2}{|c|}{ Average/trap } & \multicolumn{2}{|c|}{ Total } & \multicolumn{2}{|c|}{ Average/trap } \\
\hline 2010 & 39 & \multicolumn{2}{|c|}{1,525} & \multicolumn{2}{|c|}{39.10} & \multicolumn{2}{|c|}{679} & \multicolumn{2}{|c|}{17.41} \\
\hline 2011 & 39 & \multicolumn{2}{|c|}{405} & \multicolumn{2}{|c|}{10.38} & \multicolumn{2}{|c|}{948} & \multicolumn{2}{|c|}{24.31} \\
\hline 2012 & 39 & \multicolumn{2}{|c|}{6,861} & \multicolumn{2}{|c|}{175.92} & \multicolumn{2}{|c|}{2,05} & \multicolumn{2}{|c|}{71.92} \\
\hline 2013 & 39 & \multicolumn{2}{|c|}{26,769} & \multicolumn{2}{|c|}{686.38} & \multicolumn{2}{|c|}{1,221} & \multicolumn{2}{|c|}{31.31} \\
\hline 2014 & 38 & \multicolumn{2}{|c|}{19,938} & \multicolumn{2}{|c|}{524.68} & \multicolumn{2}{|c|}{987} & \multicolumn{2}{|c|}{25.97} \\
\hline 2015 & 32 & \multicolumn{2}{|c|}{20,670} & \multicolumn{2}{|c|}{645.94} & \multicolumn{2}{|c|}{322} & \multicolumn{2}{|c|}{10.06} \\
\hline 2016 & 32 & \multicolumn{2}{|c|}{26,337} & \multicolumn{2}{|c|}{823.03} & \multicolumn{2}{|c|}{452} & \multicolumn{2}{|c|}{14.13} \\
\hline 2017 & 32 & \multicolumn{2}{|c|}{47,088} & \multicolumn{2}{|c|}{$1,471.50$} & 9,93 & & & \\
\hline 2018 & 32 & & 98 & & & 1,17 & & & \\
\hline 2019 & 41 & & 36 & & 93 & 58 & 39 & & \\
\hline & & Min & Max & Mean & SD & Min & Max & Mean & SD \\
\hline 2010-2019 & & 10.38 & 1471.5 & 490.29 & 457.54 & 10.06 & 310.47 & 55.75 & 91.25 \\
\hline
\end{tabular}

National Oceanic and Atmospheric Administration Climate Data Online Search tool (https://www.ncdc.noaa.gov/cdo-web/ search).

Spatial analysis. GIS Esri ArcMap 10.7.1 software was used to create maps and perform all spatial functions and calculations. Total seasonal mosquito trap counts were linked to the county shapefile with $\mathrm{XY}$ coordinates (latitude, longitude) of sampling sites. All data sets were projected to the (GCS_NAD_1983_2011) geographic coordinate system and the Albers Equal Conical Area projection coordinate system (NAD_1983_2011_Florida_GDL_Albers). Portions of the base county shapefile were erased with the overlay of the waterways to clarify the boundaries of the county landmass and adulticide zones during creation of interpolation maps.

Previous entomological and vector studies have employed interpolation techniques to estimate mosquito species abundance at non-sampled locations, particularly using the inverse distance weighted (IDW) method (Allen and Shellito 2008, Cleckner et al. 2011, Sarfarz et al. 2012, Sumaye et al. 2012, Suganthi et al. 2015, Dunphy et al. 2019, Saffawati et al. 2019). IDW was chosen for these analyses due to its low processing power, comprehensiveness, and simpli- fied interpolation that does not necessitate the more sophisticated math parameters of other methods. All interpolation for mosquito abundance was performed using ArcMap 10.7.1 default settings (variable distance, twelve minimum neighbors) due to the uneven and extensive spread of sampling sites. The default decay power of two was also kept because this is within the standard range of environmental interpolation studies (literature cited above). A biologically relevant fixed distance (i.e. mosquito flight range) was not possible to include in the input parameters because the distance between most sampling sites exceeded such a distance threshold. IDW maps were created for each singled-out year (2010, 2013, 2016, 2019) or an aggregate total across the four years using georeferenced seasonal totals. For several statistical analyses, the layer attributes of estimated mosquito counts were extracted from IDW maps for 2010, 2013, and 2016 by setting the input location points as the CDC light trap sites from the 2019 surveillance season, which had the highest number of active trap sites (Fig. 2 a,b). This allowed comparison of (estimated) mosquito abundance across the timeline from locations where a trap was not permanently placed throughout the four years. 
Habitat composition analysis. This methodology was based on studies by Moncayo (2000) and Kelen et al (2012). Land use/ land cover (LULC) data sourced from the 2014 St. Johns River Water Management District (SJRWMD) LULC dataset which was downloaded from the Florida Geographic Data Library (https://www.fgdl.org/metadataexplorer/explorer.jsp). St. Johns River Water Management District provides a localized and finely detailed classification of LULC with a maximum one hundred LULC codes to describe polygon land plots. Digital orthophotography and classification of St. Johns County was accomplished by SJRWMD in 2015. There are four levels of LULC classifications defined by the SJRWMD with Level 1 being the broadest and Level 4 as the most specific. Level 2 classification codes were originally chosen but were later adjusted to resemble Level 1 codes with seven aggregated categories; (1) residential and built-up, (2) agriculture, (3) upland non-forested, (4) upland forested, (5) water, (6) wetlands, and (7) transportation, utilities, and barren.

Buffer zones were drawn around all thirty-two mosquito trapping sites from the 2016 surveillance season. Data from other surveillance years (2010, 2013, and 2019) were not included in these analyses to avoid confounding of potentially significant LULC change between years, e.g. urbanization. The buffer radii were $2.2 \mathrm{~km}$ or $1.4 \mathrm{~km}$ to account for the published flight range of Ae. atlanticus and Ae. infirmatus, respectively (Morris et al. 1991, Verdonschot and BesseLototskaya 2014). The values of the total area of Level 2 LULC codes within each buffer zone were extracted to calculate the proportions of LULC classes within the total buffer area surrounding individual CDC light trap sites. The identity tool was used for retrieval of the exact LULC classification of any individual polygon cell that contained a mosquito trap site.

Statistical analysis: For non-spatial analyses, classical Pearson's correlation was used to test the relationships between two quantitative variables (total seasonal precipitation vs total seasonal county-wide mosquito abundance, total weekly precipitation vs total weekly county-wide mosquito abundance). Precipitation was lagged at two and threeweek intervals for correlation tests with mosquito counts to account for the timespan needed for mosquito development from egg to adult. Spatially-referenced mosquito abundance at individual trap sites was represented by total seasonal counts. For habitat composition analyses and related Pearson's correlations, abundances at individual 2016 trap sites were $\log (n+1)$ transformed to achieve a more normalized distribution (Williams 1937, Bidlingmayer 1969). Mosquito abundance was separately compared against values of percent buffer coverage by each LULC class. Non-parametric statistics (Kruskal-Wallis) were used for any testing of quantitative variables between categorical groups (surveillance season) due to the nonnormal distribution of all datasets (O'Hara and Kotze 2010). All statistical tests were performed using SPSS Statistic 26 software and were species-specific.

\section{RESULTS}

Spatiotemporal patterns. Temporal: Mosquito abundance data (2010-2019) were compared by year, month, and week with measurements of average number mosquitoes per trap to account for the varied number and location of light traps across the ten years. Overall, abundance of Aedes atlanticus was higher than that of Ae. infirmatus in CDC light trap collections every year except for 2011 which had an abnormal pattern due to most traps having comparatively low or zero counts of Ae. atlanticus throughout the duration of the surveillance season. Both species demonstrated variation in total mosquito abundance across individual surveillance seasons; however, abundance trends (population rise or decline) over the decade were similar between the two species, aside from 2012-2013 and 2015-2016 when total seasonal counts of Ae. atlanticus and Ae. infirmatus contrastingly increased or decreased in number compared to the previous year (Table 1$)$. There was a positive correlation $(\mathrm{R}=$ $0.674, \mathrm{p}=0.046$ ) between the average (standardized) seasonal abundance between the 
Table 2. The Kruskal-Wallis non-parametric method was used to test for significant differences in the mean seasonal mosquito abundance between all the years 2010, 2013, 2016, and 2019 (input values as seasonal aggregates of mosquitoes collected at individual CDC light traps). Tukey's test for post hoc analysis allowed multiple pair-wise comparisons (2010 vs 2013, 2013 vs 2019, etc.) to resolve which pairs of years had statistically significantly differences. The bolded test statistics $\left(\chi^{2}, p\right.$-value $)$ represent statistical significance between samples $(n=d f+1)$.

\begin{tabular}{|c|c|c|c|c|c|c|}
\hline \multirow[b]{2}{*}{ Years compared } & \multicolumn{3}{|c|}{ Ae. atlanticus } & \multicolumn{3}{|c|}{ Ae. infirmatus } \\
\hline & $\chi^{2}$ & $\mathrm{p}$-value & df & $\chi^{2}$ & $\mathrm{p}$-value & $\mathrm{df}$ \\
\hline $2010-2019$ & 51.482 & $<0.001$ & 3 & 10.748 & 0.013 & 3 \\
\hline 2010 vs 2013 & -55.603 & $<0.001$ & 1 & -21.949 & 0.158 & 1 \\
\hline 2010 vs 2016 & -59.427 & $<0.001$ & 1 & -3.346 & 1.000 & 1 \\
\hline 2010 vs 2019 & -14.285 & 0.864 & 1 & -9.325 & 1.000 & 1 \\
\hline 2013 vs 2016 & -3.825 & 1.000 & 1 & -18.603 & 0.444 & 1 \\
\hline 2013 vs 2019 & -41.318 & $<0.001$ & 1 & -31.273 & 0.008 & 1 \\
\hline 2016 vs 2019 & -25.143 & $<0.001$ & 1 & -12.671 & 1.000 & 1 \\
\hline
\end{tabular}

two species. Aedes atlanticus often had peak activity in the latter half of the season with a gradual increase in emergence until the end of October. In contrast, average peak abundance for Ae. infirmatus typically occurred June-August and then remained low for the rest of the season. There were also week-to-week fluctuations which were not constant between years as the population growth curves of both species were highly variable over the standardized twenty-sixweek season for 2010-2019 with differences

(a)

Estimated no. mosquitoes

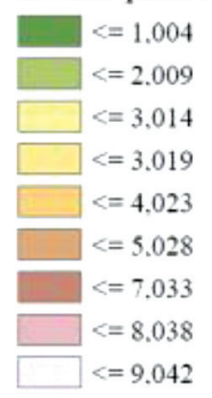

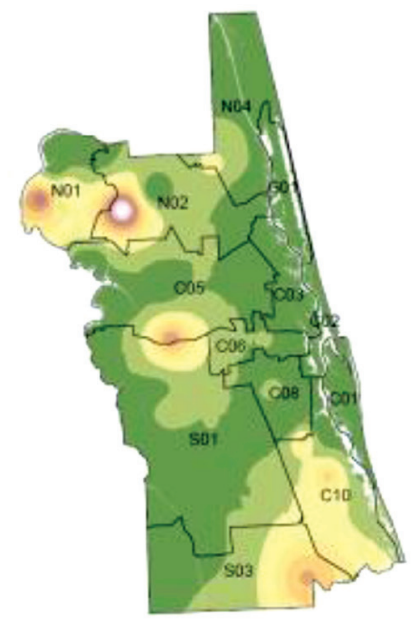

Ae. atlanticus in magnitude and seasonal timing of population peaks between years. Aedes infirmatus populations generally emerged before $A e$. atlanticus according to collection data from weeks preceding the standardized timeline. Both species reached one to several dramatic population peaks during May-November and most of these crests lasted one to two weeks until there was a noticeable decrease in the number of mosquitoes collected.

Spatial: The variation in seasonal trap collections across different traps sites (b)
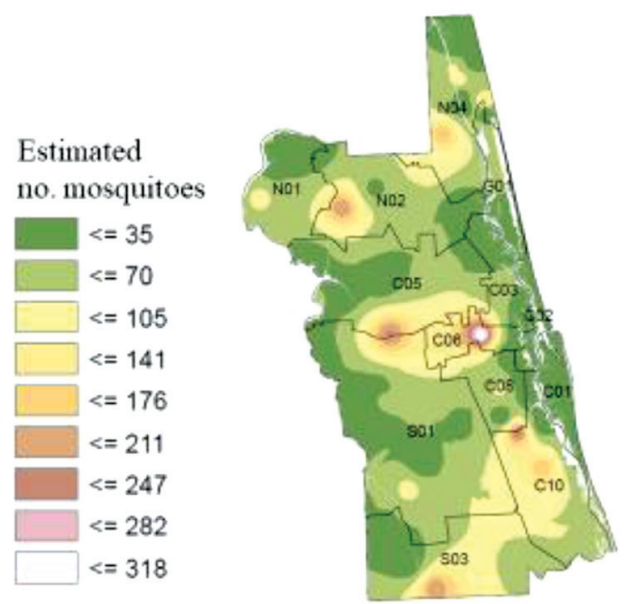

Ae. infirmatus

Figure 3. Aggregated IDW surfaces with overlay of adulticide zones: The aggregates of total seasonal counts of (a) Ae. atlanticus and (b) Ae. infirmatus, collected at all trap site locations of 2010, 2013, 2016, and 2019, were used to create an IDW surface for each species. The symbology classification was set as equal intervals and includes both the minimum and maximum values of estimated number of mosquitoes (i.e. mosquito abundance) across the county. A shapefile of AMCD's 2020 adulticide route zones was overlaid the IDW raster surfaces to outline zones with historical hotspots of mosquito populations. 


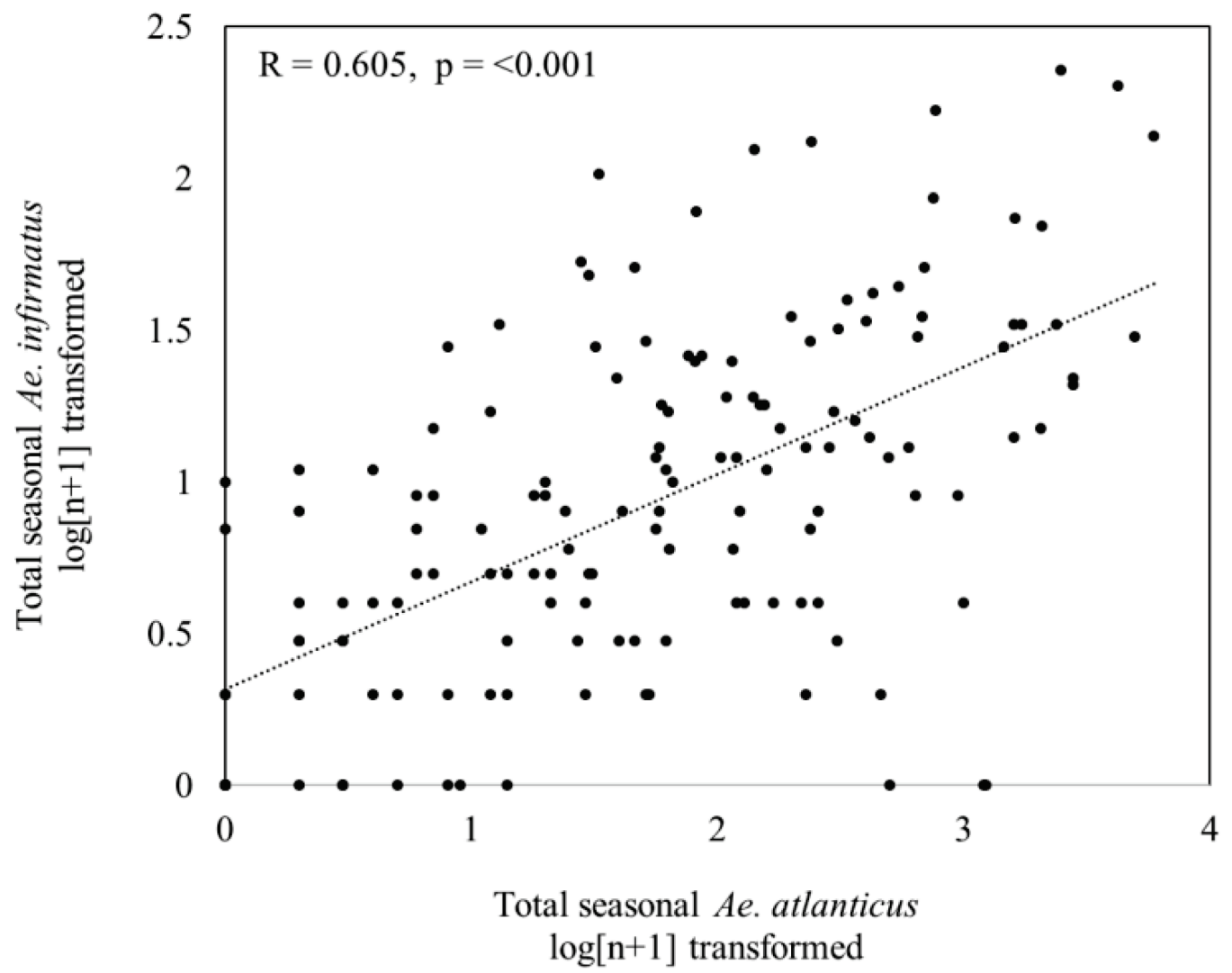

Figure 4. Spatial association of mosquito species at CDC light trap sites: Scatterplot of Ae. atlanticus versus Ae. infirmatus mosquito abundance counts $(\log [\mathrm{n}+1]$ transformed) at individual CDC light trap locations for all traps from 2010, 2013, 2016, and 2019. If a trap location was used for more than one year, each year's entry and mosquito count were counted as a new matched pair and were graphed as a separate scatter point. Results for Pearson's test for linear correlation located on plot.

(Fig. 2b) indicated a high level of spatial and temporal heterogeneity of mosquito abundance throughout St. Johns County. Total mosquito counts for each trap site for the years 2010, 2013, 2016, and 2019 were compared (Table 2). Both species had a statistically significant difference in mean seasonal abundance across the four years. For Ae. atlanticus, a Tukey post hoc test showed this difference was due to significant differences in the distributions of mosquito abundance counts between either peripheral year $(2010,2019)$ versus the middle two years (2013, 2016). There was no significant difference in county-wide abundance with 2010 vs 2019 or 2013 vs 2016. For Ae. infirmatus, the significance of the Kruskal-Wallis test was driven by a significant difference only between years 2013 vs 2019 .
IDW surface maps created with data from individual surveillance seasons showed shifting clusters of mosquito population hotspots with inconsistent intensities across the four years (data not shown). Standardization of ArcGIS classification symbology for a single species clarified the differences in expected population abundances and distributions from year to year. The maps showed evidence of differences in countywide mosquito abundance between years; however, did not show evidence of any chronologically consistent shifts in mosquito distribution over the decade. Thus, an aggregate of seasonal counts across all four years was used to create a hot spot map that defined three broad historical clusters of Ae. atlanticus and Ae. infirmatus (Fig. 3). An overlay of adulticide zones, used by the dis- 
trict to delineate areas for adulticide fogging missions, provides a map for areas to target control of these two species. Overall, the key clusters of these mosquitoes seem to overlap with noticeable differences in spread and intensity. Although the hotspots of these two species may contrast within a single year (data not shown), the aggregated maps show an overall association of the spatial presence of these species. Pearson's correlations did demonstrate a moderate positive correlation (Fig. 4) between the total seasonal abundance of Ae. atlanticus and Ae. infirmatus collected from the same site when compiled from all four years and across individual years (Table 3). Correlations with estimated abundance values that were extracted from locations of 2019 trap sites from the appropriate IDW surfaces yielded similar strengths of spatial correlation (Table 3). These linear trends indicate that the presence and population growth trends of Ae. atlanticus and $A e$. infirmatus were likely influenced by similar factors within the same geographic location.

Ecological drivers. Precipitation: One indicator of a potential driver of mosquito populations was the occurrence of large spikes in collection counts that were preceded by extreme weather events, e.g. hurricanes. Total seasonal rainfall was significantly correlated to average county-wide mosquito abundance (per all traps in one season) for Ae. atlanticus $(\mathrm{R}=0.810, \mathrm{p}=0.005)$ and Ae. infirmatus $(\mathrm{R}$ $=0.850, \mathrm{p}=0.002$ ) (Fig. 5a,b). Total weekly rainfall was inconsistently correlated to total mosquito abundance per week at both two and three-week lags in rainfall (Table 4). Outlier data points noticed in scatterplots were for the most part due to a week of heavy rainfall that also happened to be a peak rainfall week for the season. These outliers often drove the significant correlation and when removed from the data set the significance disappeared. This event happened most frequently with $A e$. atlanticus. In fact, seasonal precipitation peaks were often followed by major seasonal Ae. atlanticus population peaks. This was not as often the case for $A e$. infirmatus which often experienced population peaks long before or long after the onset of major precipitation events. All signifi- cant correlations were positive, aside from tests with 2018 Ae. infirmatus when removal of a precipitation outlier resulted in both a newly significant negative coefficient of determination at a three-week lag $(\mathrm{R}=-0.407, \mathrm{p}$ $=0.043$ ) and a switch from a significant positive to a significant negative correlation at a three-week lag $(\mathrm{R}=-0.437, \mathrm{p}=0.029)$.

Habitat composition: Population abundance of Ae. atlanticus at 2016 CDC light trap locations had a strong positive linear correlation to the percentage of buffer area filled by upland forests $(\mathrm{R}=0.806, \mathrm{p}=<0.001)$ and a strong negative correlation to the percent area covered by the LULC class of water $(\mathrm{R}=$ $-0.704, \mathrm{p}=<0.001$ ) (Fig. 6). Population abundance of Ae. infirmatus also had positive and negative correlations to percent upland forest $(\mathrm{R}=0.406, \mathrm{p}=0.021)$ and percent water $(\mathrm{R}=-0.385, \mathrm{p}=0.029)$, respectively (Fig. 7). Aedes infirmatus had an additional negative correlation to percent agriculture in the buffer zone $(\mathrm{R}=-0.428, \mathrm{p}=0.015)$. The four other LULC classes did not share any significant association with either species.

Table 3. Positive spatial association of mosquito species: Pearson's correlation was used to find best-fit line between the total Ae. atlanticus and total Ae. infirmatus collected at the same trapping location across all years (2010-2019) or within an individual season (2010, 2013, 2016, and 2019) (observed). The same tests were performed using data extractions from IDW maps made with collection records of individual surveillance seasons (IDW estimates). These estimated abundance values were extracted using the coordinates of all forty-one locations of 2019 CDC light traps.

\begin{tabular}{lcc}
\hline \hline & Observed & \\
\hline Year $(\mathrm{s})$ & $\mathrm{R}$ & $\mathrm{p}$-value \\
2010 & 0.674 & $<0.001$ \\
2013 & 0.626 & $<0.001$ \\
2016 & 0.496 & $<0.001$ \\
2019 & 0.781 & $<0.001$ \\
$2010-2019$ & 0.605 & $<0.001$ \\
\hline
\end{tabular}

\begin{tabular}{lcc}
\multicolumn{3}{c}{ IDW estimates } \\
\hline Year(s) & $\mathrm{R}$ & $\mathrm{p}$-value \\
2010 & 0.599 & $<0.001$ \\
2013 & 0.671 & $<0.001$ \\
2016 & 0.539 & $<0.001$ \\
2019 & 0.781 & $<0.001$ \\
$2010-2019$ & 0.597 & $<0.001$ \\
\hline
\end{tabular}




\section{DISCUSSION}

This study explored the spatial and temporal patterns of two poorly understood mosquito species under surveillance by AMCD mosquito control operations. It was not surprising that precipitation was found to have an impact on seasonal and weekly population abundance trends (Weaver and Xue 2015, Weaver et al. 2013, 2020). Also, the land classes of upland forest, water, and agriculture were associated with the abundance of one or both species collected at CDC light trap sites.

Aedes atlanticus and Ae. infirmatus appear to share a close spatial association without a matched temporal association. There was a clear impact of precipitation on the emergence and population growth curves of both species, but Ae. atlanticus did seem to experience a more direct impact from weekly rainfall. It is possible that the seasonal fluctuations of Ae. infirmatus are partially related to the emergence patterns of Ae. atlanticus. If Ae. atlanticus is naturally more abundant it is then more likely to exceed the action threshold for fogging missions and both populations will be reduced even if Ae. infirmatus was not at a problematic level in the first place. This idea applies to the presence of other nuisance and vector species collected by any of the surveillance trap types used by mosquito control programs. Furthermore, there is simply a lack of sufficient literature that

(a)

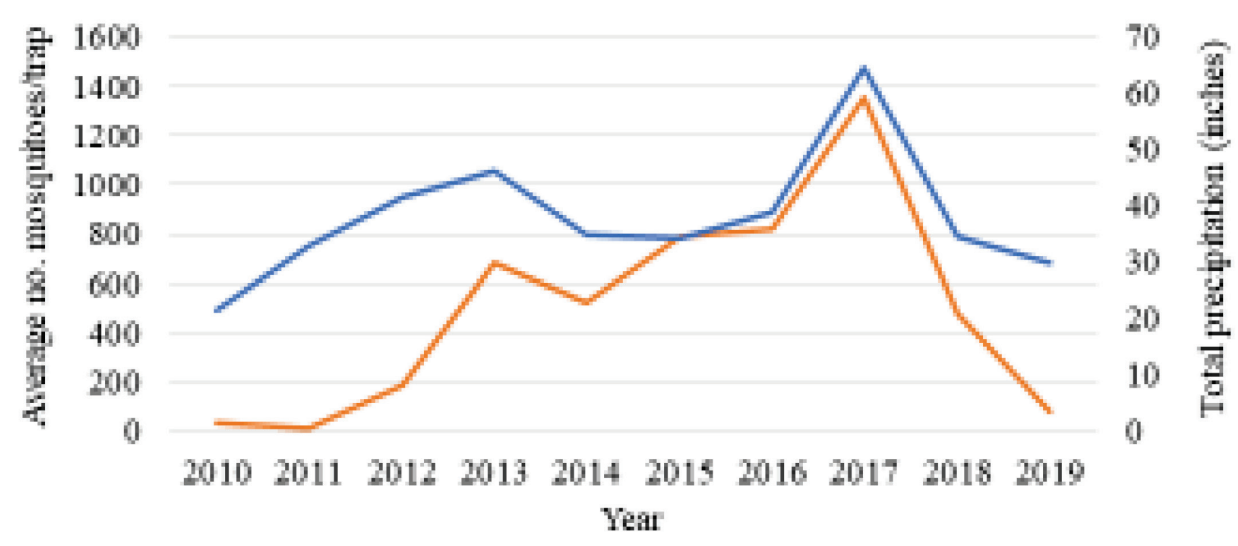

(b)
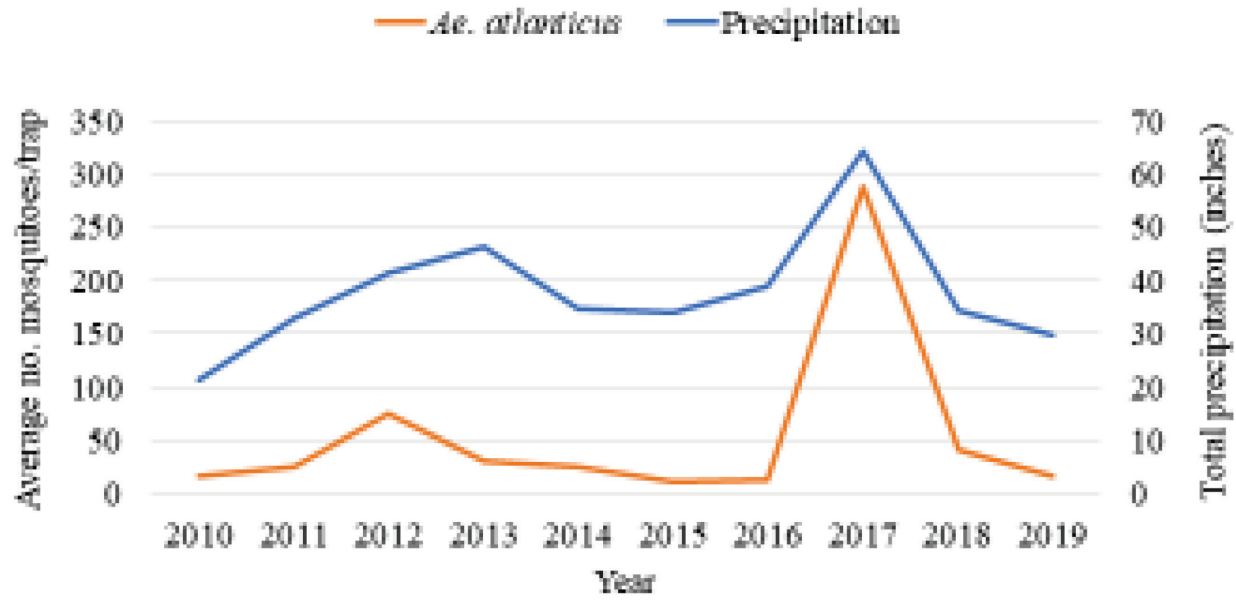

-Ae. bohwous = Predputation

Figure 5. Seasonal mosquito abundance and precipitation relationship: A line graph depicting the total seasonal precipitation and the total seasonal abundance counts of Ae. atlanticus (top) and Ae. infirmatus (bottom) averaged by number of traps sites used in an individual year, across all years 2010-2019. 
Table 4. The results of all Pearson's correlation with comparisons of total weekly precipitation and total abundance counts for a given collection week. Weekly precipitation was matched to weekly abundance counts at two- and threeweek lags. All coefficients and p-value are listed, and significant correlations are bolded. $*=$ removing outlier(s) made p-value insignificant, $* *=$ removing outlier $(\mathrm{s})$ made $\mathrm{p}$-value significant, $* * *=$ removing outlier(s) made correlation change direction.

\begin{tabular}{|c|c|c|c|c|c|c|c|c|}
\hline \multirow{3}{*}{$\begin{array}{l}\text { Precipitation } \\
\text { Year }\end{array}$} & \multicolumn{4}{|c|}{ Ae. atlanticus } & \multicolumn{4}{|c|}{ Ae. infirmatus } \\
\hline & \multicolumn{2}{|c|}{ 2-week lag } & \multicolumn{2}{|c|}{ 3-week lag } & \multicolumn{2}{|c|}{ 2-week lag } & \multicolumn{2}{|c|}{ 3-week lag } \\
\hline & $\mathrm{R}$ & p-value & $\mathrm{R}$ & p-value & $\mathrm{R}$ & p-value & $\mathrm{R}$ & p-value \\
\hline 2010 & 0.734 & $<0.001$ & -0.056 & 0.785 & 0.226 & 0.267 & -0.183 & 0.371 \\
\hline 2011 & 0.114 & 0.580 & 0.342 & 0.087 & 0.153 & 0.455 & 0.336 & $0.940 * *$ \\
\hline 2012 & 0.229 & 0.261 & 0.255 & 0.209 & 0.152 & 0.458 & 0.445 & $0.019 *$ \\
\hline 2013 & -0.209 & 0.305 & 0.663 & $<0.001 *$ & -0.072 & 0.727 & -0.066 & 0.749 \\
\hline 2014 & 0.233 & 0.252 & 0.404 & 0.040 & 0.043 & 0.836 & 0.259 & 0.201 \\
\hline 2015 & 0.504 & 0.009 & 0.096 & 0.640 & 0.237 & 0.255 & 0.176 & 0.400 \\
\hline 2016 & 0.492 & 0.130 & -0.097 & 0.637 & 0.034 & 0.868 & -0.121 & 0.556 \\
\hline 2017 & 0.347 & 0.082 & -0.050 & 0.809 & 0.177 & $0.386^{* *}$ & 0.074 & 0.719 \\
\hline 2018 & 0.796 & $<0.001 *$ & -0.040 & 0.847 & 0.627 & $0.001 * * *$ & -0.223 & $0.274 * *$ \\
\hline 2019 & 0.409 & 0.038 & 0.058 & 0.780 & 0.213 & 0.296 & 0.207 & 0.310 \\
\hline
\end{tabular}

compares the biology of these mosquitoes and most taxonomic references simply state that these two species are "associated" with one another. However, it is likely that there are significant biological and ecological differences which have yet to be investigated and would help explain the mismatches in temporal emergence and the disproportionate population abundance trends.

Previous studies have successfully utilized measurements of the life-cycle stages of eggs, larvae, or most commonly, adults, to create informative IDW models of mosquito distribution (Allen and Shellito 2008, Cleckner et al. 2011, Sarfarz et al. 2012, Sumaye et al. 2010, Suganthi et al. 2015, Dunphy et al. 2019, Saffawati et al. 2019, Kahamba et al. 2020) which lends flexibility to some of the resource limitations that may inhibit a regional mosquito control district. A major strength of spatial maps is that they can be understandable to key stakeholders and are applicable to real-time mosquito control operations, especially in relation to management of vector-borne disease (Eisen and Lorenzo-Fuentes 2009, Eisen and Eisen 2011). Unfortunately, few papers describe a specific implementation of mosquito control strategies based on IDW findings rather than simply promoting a generalized concept of potential applications. Sumaye et al (2012) created IDW surfaces with adult mosquito collections to directly aid development of a model for determining optimal deployment of mosquito control interventions (e.g. lureand-kill odor baited stations). Meanwhile, Regis et al (2013) used kernel density estimation (akin to interpolated hotspot maps) of mosquito egg abundance to help evaluate a pilot evaluation of a proposed integrated control strategy. Their spatial maps identified priority areas for control efforts, communicated findings to field workers, and aided analysis of the ongoing impact on mosquito populations by the integrated control activities. The current IDW mapping protocol developed with AMCD mosquito trap records does present real-time implications for this district's field operations by allowing more targeted intervention strategies on a week-to-week basis that optimizes the capacity of a limited field technician staff. However, a realistic form of implementation would need to be considered in terms of the operational, administrative, and regulatory systems in place at the district.

Directly compared to this study's objectives, other publications have both utilized IDW to conduct spatiotemporal analyses and have also demonstrated the impact of climatic and LULC variables on mosquito distribution (Suganthi et al. 2011, Sarfaz et al. 2012). The IDW maps of Ae. atlanticus and Ae. infirmatus here demonstrated the spatial 


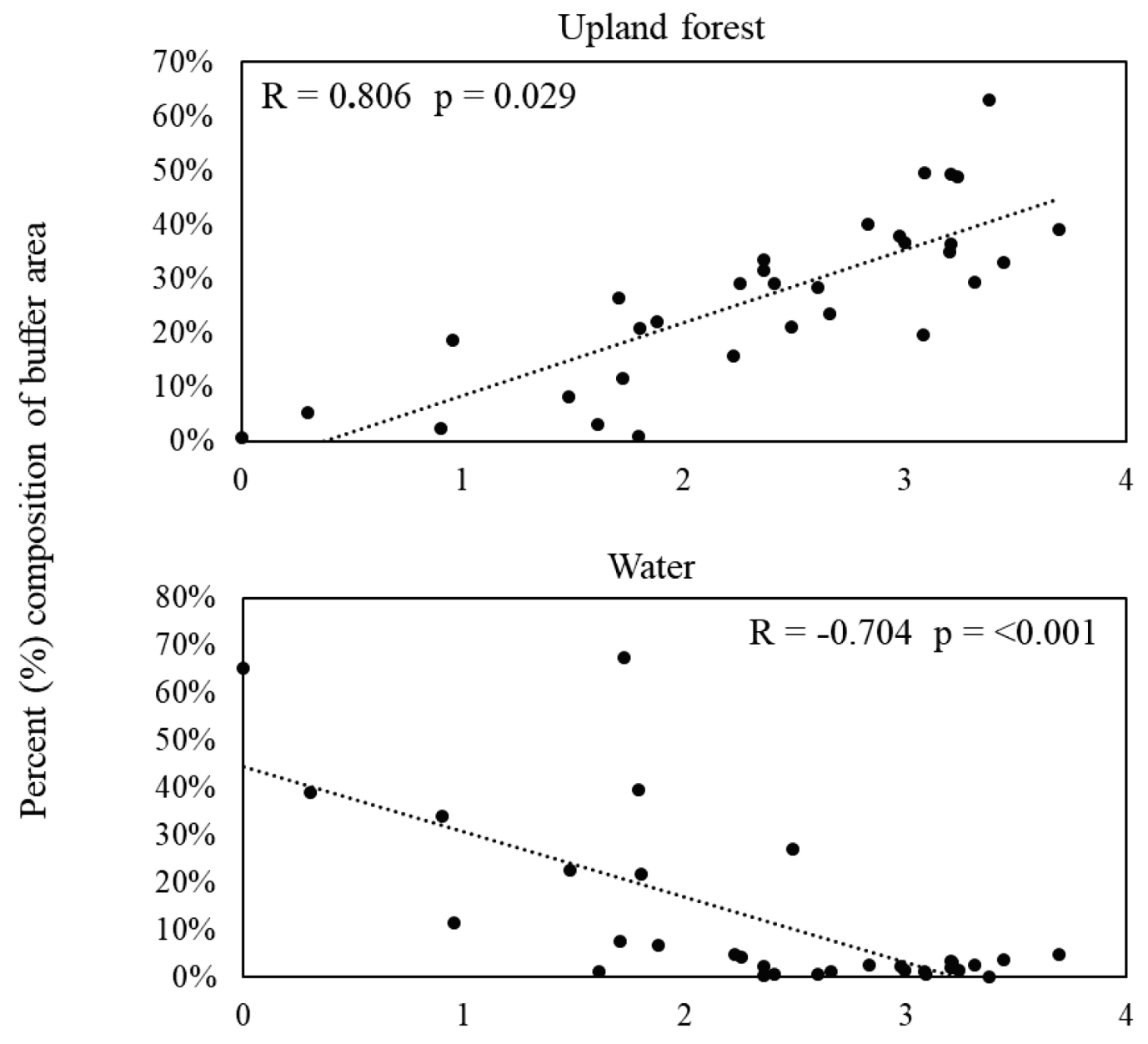

\section{Ae. atlanticus abundance $(\log [\mathrm{n}+1]$ mosquitoes $)$}

Figure 6. Habitat composition: Aedes atlanticus: Scatter plots with best-fit lines displaying the association between seasonal abundance $(\log (n+1)$ transformed) of Aedes atlanticus at a 2016 CDC light trap site and percent composition of the buffer area covered by a land cover class.

heterogeneity of species abundance in St. Johns County while habitat composition analyses then clarified likely drivers of this spatial variation, for example the result that CDC light traps sites surrounded by upland forest had collected significantly more $A e$. atlanticus and Ae. infirmatus. The simplified LULC class 'Upland Forest' in this report includes the subset class coniferous forest, upland hardwood forest, mixed, and tree plantations. Tree plantations are the predominate Level 2 LULC class for St. Johns County (data not shown) and it is worthwhile to further examine this relationship to upland forest further because of the likely county-wide risk of mosquito emergence and distribution. The negative correlation with water is rational because this LULC class was an umbrella class and included lakes, reservoirs, bays, estuaries, streams, waterways, enclosed saltwater ponds, major springs, and slough waters. These are considered moving water or permanent water bodies, none of which are indicated to be the preferred ecological niche of Ae. atlanticus or Ae. infirmatus (Burkett-Cadena 2013). The negative association with agriculture with only $A e$. infirmatus is another curiosity. One notable 
Upland forest



Ae. infirmatus abundance $(\log [\mathrm{n}+1]$ mosquitoes)

Figure 7. Habitat composition: Aedes infirmatus: Scatter plots with best-fit lines displaying the association between seasonal abundance $(\log (\mathrm{n}+1)$ transformed) of Aedes infirmatus at a $2016 \mathrm{CDC}$ light trap site and percent composition of the buffer area covered by a land cover class. 
limitation of all habitat composition tests is that there was lack of consideration of the percent of other classes in a buffer which is a potential statistical issue since the proportion of a LULC class is inherently affected by the proportion of others.

This project compiled and utilized publicly available databases and developed protocols to manipulate historical mosquito control datasets. In addition, there is a large volume of additional historical data that was left out of this project, including AMCD surveillance reports from 2004-2009. One important research direction is to analyze the impact and effectiveness of direct mosquito control pesticide application efforts throughout St. Johns County. This type of evaluation is lacking in the literature and could add real value to programs with fewer resources and less capacity. Also, the observed relationship of mosquito collections to precipitation implicates the usefulness for a spatial study that specifically tracks and compares the historical emergence locations of nuisance and vector species after extreme historical weather events such as hurricanes. Recommendations for future projects are to develop stronger statistical models using multiple linear regression to better represent the complex hierarchy of climate, environment, and mosquito species dynamics more accurately. Trends in spatial distribution might be best described over a longer time than 2010-2019 or be better represented with spatial maps for continuous years. The last consideration involves developing a pragmatic integration of spatial density maps into real-time control operations and stakeholder participation. It is necessary for any interested program to account for the feasible quantity and geographic spread of light traps and to focus on reaching sufficient coverage and reliability in the areas with the greatest density of vulnerable residents.

\section{ACKNOWLEDGEMENTS}

We thank J.R. Weaver and M.K. Gaines for their background knowledge of AMCD operations and provision of access to AMCD historical data archives. We also thank L.
Mao, J. Aufmuth and D. Maxwell from the University of Florida for all their guidance and feedback concerning data manipulations, ArcGIS software, and statistics. There are no conflicts of interest to report. This research was supported/funded by the Department of the Army, U.S. Army Contracting Command, Aberdeen Proving Ground, Natick Contracting Division, Ft. Detrick, MD under Deployed War Fighter Protection (DWFP) Program W911QY2010004 awarded to AMCD.

\section{REFERENCES CITED}

AMCD. n.d. 2017 annual program report [Internet]. Anastasia Mosquito Control District. [accessed May 2020]. https://amcdsjc.org/district/annualreports/

Allen T, Shellito B. 2008. Spatial interpolation and image-integrative geostatistical prediction of mosquito vectors for arboviral surveillance. Geocarto Int 23: 311-325. doi:10.1080/10106040801953488

Bigler WJ, Lassing EB, Buff EE, Prather EC, Beck EC, Hoff GL. 1976. Endemic eastern equine encephalomyelitis in Florida: a twenty-year analysis, 19551974. Am J Trop Med Hyg 25: 884-890. doi:10.4269/ ajtmh.1976.25.884

Bidlingmayer WL. 1969. The use of logarithms in analyzing trap collections. Mosq News. 29:635-40. Burkett-Cadena N. 2013. Mosquitoes of the southeastern United States. (1 ed.). Tuscaloosa: The University of Alabama Press, AL. 188 pp.

Cleckner H, Allen T, Bellows A. 2011. Remote sensing and modeling of mosquito abundance and habitats in coastal Virginia, USA. Remote Sens 3:2663-2681.

Darsie Jr. RF, Ward RA. 2005. Identification and geographical distribution of the mosquitoes of North America, north of Mexico. University Press of Florida, FL. 398 pp.

Dunphy BM, Kovach KB, Gehrke EJ, Field EN, Rowley WA, Bartholomay LC, Smith RC. 2019. Long-term surveillance defines spatial and temporal patterns implicating Culex tarsalis as the primary vector of West Nile virus. Sci Rep 9: 6637.

Eisen L, Eisen R. 2011. Using geographic information systems and decision support systems for the prediction, prevention, and control of vector-borne diseases. Annu Rev Entomol 56: 41-61.

Eisen L, Lozano-Fuentes S. 2009. Use of mapping and spatial and space-time modeling approaches in operational control of Aedes aegypti and dengue. PLoS Neglect Trop D 3:e411.

Florida Health Charts. n.d. Population Atlas [Internet]. Available from the Florida Department of Health [accessed September 20, 2020]. http:/ / www. flhealthcharts.com/charts/PopulationCharacteristics/default.aspx.

Hungerford LL. 1991. Use of spatial statistics to identify and test significance in geographic disease patterns. Prev Vet Med 11: 237-242.

Kahamba N, Limwagu A, Mapua S, Msugupakulya B, Msaky D, Kaindoa E, Ngowo H, Okumu, Fredros. 2020. Habitat characteristics and insecticide suscep- 
tibility of Aedes aegypti in the Ifakara area, south-eastern Tanzania. Parasites and Vectors 13.

Kelen PT, Downs JA, Burkett-Cadena ND, Ottendorfer CL, Hill K, Sickerman S, Hernandez J, Jinright J, Hunt B, Lusk J, Hoover V, Armstrong K, Unnasch RS, Stark LM, Unnasch TR. 2012. Habitat associations of eastern equine encephalitis transmission in Walton County Florida. J Med Entomol 49: 746-756.

LeDuc JW, Burger JF, Eldridge BF, Russell PK. 1975. Ecology of Keystone virus, a transovarially maintained arbovirus. Ann N Y Acad Sci 266: 144-151.

Moncayo AC, Edman JD, Finn JT. 2000. Application of geographic information technology in determining risk of eastern equine encephalomyelitis virus transmission. J Am Mosq Control Assoc 16: 28-35.

Morris CD, Larson VL, Lounibos LP. 1991. Measuring mosquito dispersal for control programs. J Am Mosq Control Assoc. 7: 608-615.

O'Hara RB, Kotze DJ. 2010. Do not log-transform count data. Methods Ecol Evol.1:118-22.

Regis LN, Acioli RV, Silveira JC Jr, Melo-Santos MA, Souza WV, Ribeiro CM, da Silva JC, Monteiro AM, Oliveira CM, Barbosa RM, Braga C, Rodrigues MA, Silva MG, Ribeiro PJ Jr, Bonat WH, de Castro Medeiros LC, Carvalho MS, Furtado AF. 2013. Sustained reduction of the dengue vector population resulting from an integrated control strategy applied in two Brazilian cities. PloS One 8:e67682.

Roberts DR, Scanlon JE. 1975. The ecology and behavior of Aedes atlanticus D. \& K. and other species with reference to Keystone virus in the Houston area, Texas. J Med Entomol 12:537-546.

Saffawati T, Ismail T, Kassim NF, Rahman AA, Hamid SA, Yahya K, Webb CE. 2019. The application of geographic information system (GIS) to assess the population abundance of Aedes albopictus (Skuse) in mangrove forests of Penang, Malaysia. Int J Mosq Res 6: 50-54.

Sallam MF, Xue RD, Pereira RM, Koehler PG. 2016. Ecological niche modeling of mosquito vectors of West Nile virus in St. Johns County, Florida, USA. Parasites and Vectors 9:371.

Sallam MF, Lippi C, Xue RD. 2016a. Spatial analysis of arbovirus transmission in St. Johns County, Florida. Tech Bull Fla Mosq Control Assoc 10:18-29.

Sarfraz MS, Tripathi NK, Tipdecho T, Thongbu T, Kerdthong P, Souris M. 2012. Analyzing the spatio- temporal relationship between dengue vector larval density and land-use using factor analysis and spatial ring mapping. BMC Public Health 12: 853.

Suganthi P, Govindaraju M, Devi BS, Kangabam RD, Suganthi K, Thenmozhi V, Tyagi BK. 2015. Mapping of spatio-temporal distribution of mosquito vector density in Sitheri Hills using GIS technology. IJARSG 4: 873-882.

Sumaye R, Lwetoijera D, Madumla E, Okumu F. 2012. A geographical location model for targeted implementation of lure-and-kill strategies against diseasetransmitting mosquitoes in rural areas. Malaria World Journal 3:1.

United States Environmental Protection Agency. n.d. Level III and IV ecoregions of Florida [Internet]. Available from the United States Environmental Protection Agency [accessed September 20, 2020]. https://www.epa.gov/eco-research/ecoregiondownload-files-state-region-4

Verdonschot PFM, Besse-Lototskaya AA. 2014. Flight distance of mosquitoes (Culicidae): a metadata analysis to support the management of barrier zones around rewetted and newly constructed wetlands. Limnologica 45: 69-79.

Williams CB. 1937. The use of logarithms in the interpretation of certain entomological problems. Ann Appl Biol. 24:404-14.Weather Atlas. n.d. Monthly weather forecast and climate St. Augustine, FL [Internet]. Weather Atlas. [accessed September 20, 2020]. https://www.weather-us.com/en/floridausa/st-augustine-climate\#temperature.

Weaver JH, Phillips JD, Gaines MK, Xue RD. 2013. An analysis of Anastasia Mosquito Control District's service requests over the past 8 years. Wing Beats 24:3439.

Weaver JH, Xue RD. 2015. Major impact of ground application of larvicides at Anastasia Mosquito Control District, Wing Beats 26:11-15.

Weaver JR, Xue RD, Gaines KM. 2020. Population outbreaks of mosquitoes after Hurricane Matthew and Irma and the control efforts in St. Johns County, Northeastern Florida. J Am Mosq Control Assoc (in print).

Wellings FM, Lewis AL, Pierce LV. 1972. Agents encountered during arboviral ecological studies: Tampa Bay area, Florida, 1963 to 1970. Am J Trop Med Hyg 21: 201-213. 